\title{
INVESTIGATION OF PERFORMANCES OF INNOVATIVE AERONAUTIC INJECTION SYSTEMS USING ADVANCED LASER DIAGNOSTICS
}

\section{Orain, F. Grisch, E. Jourdanneau, B. Rossow, C. Guin, and B. Trétout}

Office National d'Etudes et de Recherches Aérospatiales Chemin de la Hunière, Palaiseau 91761, France

\begin{abstract}
Simultaneous measurements of Planar Laser-Induced Fluorescence (PLIF) kerosene and PLIF-OH have been successfully performed in a multipoint injection system for various overall equivalence ratios, air inlet temperatures between 480 and $730 \mathrm{~K}$, and pressures up to $2.2 \mathrm{MPa}$. Single-shot two-dimensional (2D) maps of the spatial distribution of kerosene vapor and $\mathrm{OH}$ radical in the combustor have been recorded with good signal-to-noise ratio. Results show that depending on the split between the pilot and the main injectors, the flame front exhibits either a single or a double structure. Good spatial correlation between the repartition of kerosene vapor and the position of the flame front was observed; in particular, no "dark zone" is observed between the fuel and the flame front. As temperature and pressure increase, fuel evaporation improves and the spatial distribution of $\mathrm{OH}$ radical becomes more homogeneous in the combustor, suggesting a partially-distributed combustion.
\end{abstract}

\section{INTRODUCTION}

Increasingly stringent regulations on pollutant emissions, such as $\mathrm{NOx}, \mathrm{COx}$ and soot, require improvements in combustion efficiency and overall operability of kerosene-fuelled aeronautical gas turbines. Among key parameters likely to fulfil these goals, the injection system performance is one of the issues where substantial improvements can still be achieved. It is well known that atomization of liquid sprays (shear-coaxial injectors) occurs via different physical processes compared to breakup of liquid sheets (film injectors), which often results in different droplet size, velocity, and density [1, 2]. Therefore, optimizing the

This is an Open Access article distributed under the terms of the Creative Commons Attribution-Noncommercial License 3.0, which permits unrestricted use, distribution, and reproduction in any noncommercial medium, provided the original work is properly cited. 
atomization of liquid fuel into fine droplets and their subsequent evaporation are of great importance for fuel spatial distribution within the combustor $[3,4]$.

Efficient mixing between preheated combustion air and fuel vapor generated by droplet evaporation is also crucial to combustion efficiency. First, it is crucial in terms of pollutant emissions which can be greatly reduced if the spatial distribution of air/fuel mixture in the combustor is homogeneous with lean equivalence ratio. This yields a lower flame temperature (1500-1800 K); hence, lower NOx emissions, and the absence of fuel-rich pockets leads to reduced soot formation. Second, it is crucial in terms of combustion instabilities which are known to partly depend on temporal and spatial inhomogeneities of the air/fuel mixture in the combustion chamber. Such instabilities are naturally not compatible with standards of reliability, durability, and drivability required for aircrafts engines and, therefore, must be avoided.

Over the last two decades, intense research has been dedicated to improvements of existing injection systems and to innovative designs. This has led to new concepts like multipoint, LP (Lean Premixed), and LPP (Lean Premixed Prevaporized) injectors which contribute to match the targeted goals of future regulations on pollutants emissions [5]. The principle of these injectors is to atomize the liquid fuel into small droplets which evaporate to a large extent, and mix the subsequent fuel vapor with air in a prevaporizing/premixing duct, in order to obtain a fairly homogeneous air/fuel mixture before combustion.

Many experiments have used laser-based techniques to determine the influence of parameters like droplet size and velocity, air temperature, fuel and air flowrates on the performances of such injectors $[6,7]$. However, these studies were mainly focused on the spatial distribution of liquid phase in the combustor, and the evolution of droplet size at different locations from the injector exit was used to estimate the extent of fuel evaporation [8, 9]. Indeed, only few experiments were performed to characterize fuel vapor phase $[10,11]$. In addition, results were typically obtained with surrogate fuels or added tracers which were not necessarily representative of typical fuels used in aircraft engines (i. e., kerosene). Therefore, it might happen that the conclusions drawn from these experiments were biased by the type of fuel used, because of the different rates of evaporation and combustion processes of surrogates or tracers compared to those of real fuels.

Only very few examples of studies performed with laser-based diagnostics directly applied to kerosene vapor are available in the literature $[12,13]$. Unfortunately, these results were only qualitative, because kerosene spectroscopy was not properly established despite the pioneering work of Löfström et al. [14]. Arnold et al. [15] also applied PLIF to fuel-oil detection in gas turbines for temperatures between 360 and $486{ }^{\circ} \mathrm{C}$ at atmospheric pressure. The authors have indicated that PLIF could enable equivalence ratio measurements within a 25 percent error. Recently, Baranger et al. [16] have thoroughly investigated 
photophysics of kerosene for various conditions in terms of temperature, pressure, and oxygen molar fraction, with a 266-nanometer excitation wavelength. Dependence of kerosene fluorescence on the above parameters was measured and the molecular species responsible for this fluorescence were identified.

Using the spectroscopic results of Baranger et al. [16], Orain et al. [17] have derived a quantitative strategy for measuring local equivalence ratio in kerosenefuelled gas turbines using PLIF-kerosene. The technique was applied to an LPP injector operating with jet A1 fuel at atmospheric pressure for nonreactive conditions, at temperatures between 500 and $730 \mathrm{~K}$ and overall equivalence ratio in the range $0.12-0.44$. The influence of these parameters on the spatial distribution of local equivalence ratio in the combustor was investigated. However, these experiments were performed without combustion, at low pressure and, therefore, there was a need to assess the capability of the technique to measure fuel vapor concentration at high pressure in firing conditions. Characterizing the performances of aircraft injectors also requires the determination of the flame structure and flame reaction rate, which gives information about combustion efficiency depending on operating conditions. This can be classically performed using PLIF applied to $\mathrm{OH}$ radical [18] and the technique has already been applied to pressure larger than 1.0 $\mathrm{MPa}[19,20]$. However, it is interesting to determine the spatial and temporal correlation between fuel vapor distribution and flame structure. Such information can be obtained by means of simultaneous measurements of kerosene vapor and $\mathrm{OH}$ radical in the combustor, and this can be used to evaluate the influence of fuel concentration on local flame reaction rate.

The goal of the present experiments was to combine PLIF-kerosene and PLIF$\mathrm{OH}$ in order to measure simultaneously the local equivalence ratio and spatial distribution of $\mathrm{OH}$ radical in a fired high-pressure combustor operating with jet A1 fuel. The techniques were successfully applied at temperatures between 480 and $730 \mathrm{~K}$ and pressures up to $2.2 \mathrm{MPa}$.

The paper comprises four more sections. The next section briefly recalls the photophysics of aromatics fluorescence for application to kerosene-fuelled combustors. The third section presents the combustor facility and describes the optical setup. In the forth section, the technique is subsequently applied to a high-pressure kerosene-fuelled multipoint injector. The paper ends with the summary of main findings.

\section{PLANAR LASER-INDUCED FLUORESCENCE FOR KEROSENE VAPOR MEASUREMENTS}

In a typical PLIF experiment, the flow is illuminated by a laser sheet which wavelength is tuned to excite a particular transition of a molecular tracer, which can be a species naturally-produced in the flow (e.g., $\mathrm{CH}, \mathrm{OH}, \mathrm{C}_{2}, \mathrm{CO}$, etc.) 
or seeded into the flow (e.g., $\mathrm{I}_{2}, \mathrm{O}_{2}$, NO, aldehydes, ketones, aromatics, etc.). A fraction of the molecules in the lower energy level absorbs the incident light and is promoted to a higher energy level. Some of the excited molecules photodissociate or return to equilibrium, either by emitting photons or by transferring the excess energy through nonradiative decay processes (collisional quenching, intersystem crossing, internal conversion, or vibrational relaxation).

For a weak laser excitation, the fluorescence signal intensity can generally be expressed as [18]:

$$
I=\eta_{\mathrm{opt}} \frac{E}{h c / \lambda} V_{c} N_{\mathrm{abs}} \sigma(\lambda, T) \frac{k_{f}}{k_{f}+k_{n r}+\sum_{q} k_{q} X_{q}}
$$

where $\eta_{\text {opt }}$ is the overall efficiency of the collection optics; $E$ is the laser fluence $\left(\mathrm{J} / \mathrm{cm}^{2}\right) ; h c / \lambda$ is the photon energy $(\mathrm{J})$ at the excitation wavelength $\lambda$; and $V_{c}$ is the collection volume $\left(\mathrm{cm}^{3}\right)$. The quantities that can vary with gas dynamic parameters (temperature $T$, total pressure $P$, and mixture composition) are $N_{\text {abs }}$, the number density of absorbing molecules $\left(\mathrm{cm}^{-3}\right) ; \sigma$, the molecule absorption cross section $\left(\mathrm{cm}^{2}\right) ; k_{f}$, the spontaneous emission rate; $k_{n r}$, the upper-level decay rate owing to collisionless processes (such as intersystem crossing, photodissociation, or vibrational relaxation), and $k_{q}$, the collisional-quenching rate; $X_{q}$ is defined as the molar fraction of the quenching species. In the case of kerosene, which is mainly composed of aliphatic and aromatic molecules, fluorescence typically arises from the excitation of aromatics [16]. It is well known from the literature that oxygen is the main quencher for the fluorescence of aromatics [21, 22] and that other species like $\mathrm{H}_{2} \mathrm{O}, \mathrm{CO}$, or $\mathrm{CO}_{2}$ have little influence. Therefore, $X_{q}$ will be denoted as $\mathrm{X}_{\mathrm{O}_{2}}$ in the following.

The expression of Eq. (1) can be used to derive strategies for imaging quantities such as equivalence ratio and temperature, which completely characterize spray evaporation only in the mixing regions of nonburning and burning sprays upstream from the flame front. In these specific regions, oxygen can be considered as the main quencher of kerosene fluorescence and, therefore, Eq. (1) can be applied. Visualization of mixing process requires simultaneous $2 \mathrm{D}$-imaging of fuel and oxygen concentrations in the flow with temporal resolution faster than the timescales of mixing and chemical reaction. Most simply, the fluorescence signal is seen to be a specific function of $T, \mathrm{X}_{\mathrm{O}_{2}}$, and $X_{\text {fuel }}$ for a particular excitation wavelength. Detection of fluorescence from aromatics with one excitation wavelength over two specific spectral ranges can provide dual-parameter imaging, yielding, for example, equivalence ratio in addition to temperature. Collection of kerosene and di-aromatics fluorescence signals on two separate Intensified Charged Coupled Device (ICCD) cameras with appropriate spectral filters may be one of the possibilities because of their different temperature and oxygen dependencies. Using experimentally-determined behavior of kerosene 


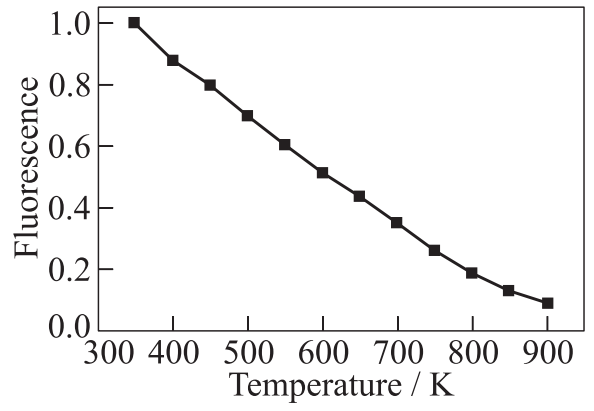

(a)

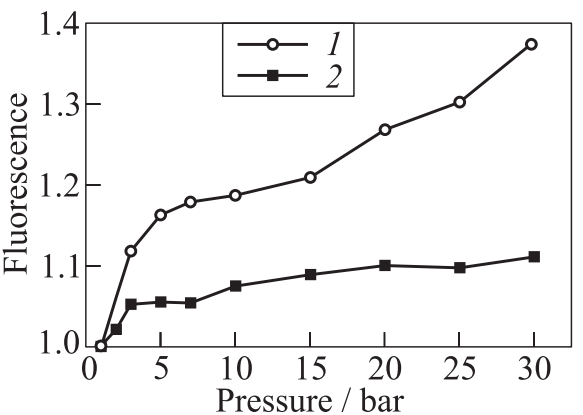

(b)

Figure 1 Evolution of integrated fluorescence of di-aromatics in $\mathrm{N}_{2}$ with temperature at atmospheric pressure $(a)$ and with pressure for two temperatures $(b): 1-700 \mathrm{~K}$; and $2-450 \mathrm{~K}$

fluorescence [16], along with a calibration point in a reference flow where thermodynamic parameters are well known, an iterative processing routine of both instantaneous fluorescence signals, combined with the closure relation for species composition (i.e., $X_{\text {fuel }}+\mathrm{X}_{\mathrm{O}_{2}}+\mathrm{X}_{\mathrm{N}_{2}}=1$ ) is then used to determine the desired quantities. Note that this data reduction implies that the ratio between monoaromatics and di-aromatics remains constant during the experiments. This assumption remains valid for temperatures up to 1100-1300 K where kerosene pyrolysis can be observed.

Additional spectroscopic measurements to those of Baranger et al. [16] have been performed in a test cell at high temperatures and pressures. For instance, Fig. 1 represents the evolution of integrated fluorescence from di-aromatics with temperature and pressure in $\mathrm{N}_{2}$ atmosphere. As can be seen, fluorescence intensity decreases by about $55 \%$ as temperature increases from 450 to $700 \mathrm{~K}$, which corresponds to the range of interest for PLIF measurements in gas turbines. This indicates that temperature has some influence on the fluorescence di-aromatics, although the signal reduction with temperature remains somehow limited. Figure $1 b$ shows that fluorescence from di-aromatics increases with pressure for different temperatures, and the gradient is stronger below 0.5 MPa. Together with the results in Fig. 1a, this allows one to estimate the evolution of fluorescence signal with temperature and pressure for a given concentration of kerosene vapor. For example, fluorescence intensity per molecule is reduced by a factor of 2 as temperature and pressure change from $450 \mathrm{~K}$ and $0.5 \mathrm{MPa}$ to $700 \mathrm{~K}$ and 2.0 $\mathrm{MPa}$. This indicates that fluorescence signals remain easily detectable at high temperature and pressure, and gives us confidence about the applicability of PLIF-kerosene to operating conditions representative of aeronautical gas turbines. 


\section{EXPERIMENTAL SETUP}

\subsection{Combustor Facility}

The combustor used in the experiments is schematized in Fig. 2. It is connected to the so-called "M1 test bench," which is the high-temperature-high-pressure combustion facility from ONERA-Palaiseau dedicated to the investigation of aircraft and helicopter injectors under real operating conditions. This bench consists of a heat exchanger which can preheat air up to $900 \mathrm{~K}$ for air flowrates up to $1 \mathrm{~kg} / \mathrm{s}$. Preheated air is injected into the combustor together with liquid kerosene via two injectors: a single pilot injector is located on the combustor axis and it is used to stabilize the flame whereas a multipoint main injector is located at a larger radial distance. Fuel flowrate is split between the two injectors and the ratio between the equivalence ratio from the pilot and the main injector $\left(\Phi_{\text {pilot }} / \Phi_{\text {main }}\right)$ lies between 0.1 and 1 , except for a condition where only the pilot injector is used (Table 1). The combustor comprises a watercooled visualization sector which is equipped with three optical accesses for laser measurements. Optical windows are made of ultraviolet (UV) silica. One is used for laser access and two others for detecting fluorescence from kerosene and $\mathrm{OH}$ radical. Optical accesses are specifically designed so that fluorescence can be collected directly at the outlet of the injector. The outlet of the combustor is equipped with a sonic throttle which can be partly obstructed by a water-cooled needle in order to control the pressure inside the combustor. Finally, exhaust gases are collected by a fan. Air inlet temperature varies between 480 and $730 \mathrm{~K}$ and pressure inside the combustor is in the range $0.45-2.2 \mathrm{MPa}$.

Table 1 summarizes the operating conditions presented in this paper. In the following, $\Phi_{\text {pilot }}$ is the equivalence ratio of the pilot injector and $\Phi_{\text {main }}$ refers to the equivalence ratio of the main injector.

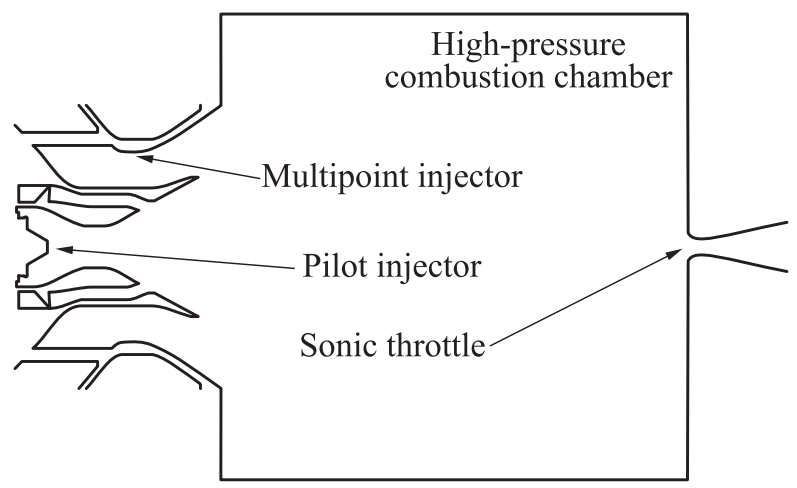

Figure 2 Schematic of the combustor (not to scale) 
Table 1 Operating conditions

\begin{tabular}{ccc}
\hline Temperature, $\mathrm{K}$ & Pressure, $\mathrm{MPa}$ & $\Phi_{\text {pilot }} / \Phi_{\text {main }}$ \\
\hline 480 & 0.45 & Pilot only \\
590 & 0.95 & 1 \\
730 & 2.2 & 0.1 \\
\hline
\end{tabular}

\subsection{Optical Setup}

Two pulsed laser systems are used to perform OH and kerosene vapor PLIF measurements simultaneously (Fig. 3). Both systems are installed in an optical room located close to the test bench. Measurements of $\mathrm{OH}$ radical are performed using a frequency-doubled, Q-switched Nd:YAG laser to pump a dye laser. The laser is frequency doubled to deliver wavelengths in the 280-290-nanometer spectral range, with energy of $20 \mathrm{~mJ}$ per pulse. The dye laser is tuned to $282.75 \mathrm{~nm}$ to excite the $\mathrm{Q}_{1}(5)$ line of the $(1,0)$ band of the $\mathrm{OH}\left(\mathrm{X}^{2} \Pi-\mathrm{A}^{2} \Sigma^{+}\right)$system. A part of the laser beam is directed to the burnt gases of a reference laminar premixed methane-air flame in order to tune the laser to the aforementioned $\mathrm{OH}$ transition. The linewidth is estimated to be approximately $0.1 \mathrm{~cm}^{-1}$ by recording the spectral profile of several $\mathrm{OH}$ transitions in the reference flame. The $\mathrm{Q}_{1}(5)$ transition is chosen because of its high intensity, its well-isolated spectral feature, and its low dependence upon temperature.

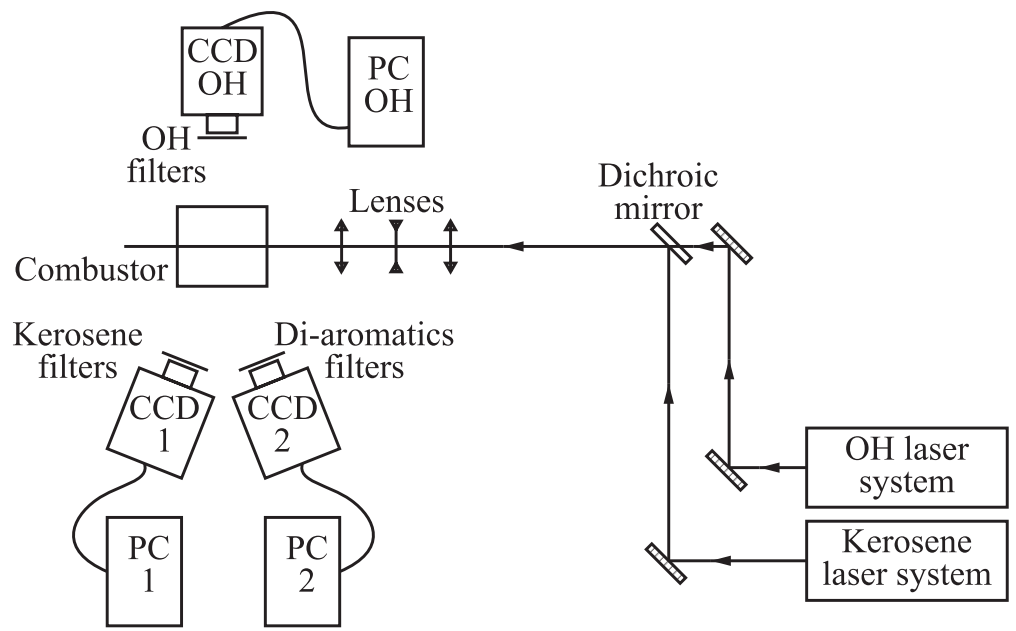

Figure 3 Optical setup for the simultaneous detection of $\mathrm{OH}$ radical and kerosene vapor fluorescence 
Measurements of kerosene fluorescence use a single-excitation scheme which comprises a frequency-quadrupled Nd:YAG laser generating 8-nanosecond, 50millijoule pulses at $266 \mathrm{~nm}$. Energy of both laser beams is controlled during the experiments by means of laser power meters. Time delay between the two laser beams is fixed to $200 \mathrm{~ns}$ in order to avoid cross-talks between fluorescence signals of $\mathrm{OH}$ and kerosene. This duration is much shorter than the typical flow timescale, ensuring that images of $\mathrm{OH}$ and kerosene fluorescence are representative of the same phenomenon at the time of recording.

Both laser beams are transported via optical mirrors around the combustor facility and superimposed with a combination of dichroic mirrors. They are then transformed into two superimposed collimated sheets using a unique set of cylindrical and spherical lenses. The two cylindrical lenses form a telescope which spreads the beams into collimated sheets. Only the central zone of the laser sheets is used to obtain laser sheet energy profiles as flat as possible, allowing, in the first assumption, proportionality between the fluorescence signals and the probe species concentration. A spherical lens with 1-meter focal length finally focuses the two sheets to a 130-micron waist located in the center of the combustion chamber. Energy in the laser sheet is maintained to $4 \mathrm{~mJ}$ for $\mathrm{OH}$ and $25 \mathrm{~mJ}$ for kerosene vapor detection, respectively.

Fluorescence from $\mathrm{OH}$ radicals is recorded with a 16-bit ICCD camera while fluorescence from kerosene vapor and liquid phases are simultaneously recorded by two 16-bit ICCD cameras (see Fig. 3). The camera used for $\mathrm{OH}$ visualization has a CCD array of $1024 \times 1024$ pixels, a temporal gate of $40 \mathrm{~ns}$, with a framing rate of $4 \mathrm{~Hz}$ and it is equipped with a 105-millimeter, $f / 4.5 \mathrm{UV}-\mathrm{NIKKOR}$ lens. The cameras used for kerosene detection have a CCD array of $512 \times 512$ pixel, a temporal gate of $40 \mathrm{~ns}$, with a framing rate of $4 \mathrm{~Hz}$, and each camera is equipped with a $f=94 \mathrm{~mm}$, achromatic UV lens.

For $\mathrm{OH}$ measurements, the camera has a combination of colored glass filters (WG 295 and UG 5 from Schott) and an interferential filter centered at $310 \mathrm{~nm}$ (full width of half maximum FWHM $=5.6 \mathrm{~nm}$ ). This allows one to spectrally remove Mie scattering and to collect only fluorescence from $\mathrm{OH}$ radical.

For kerosene measurements, both ICCD cameras are equipped with combinations of colored glass filters. The first camera is equipped with a custom-made bandpass filter in the range $260-420 \mathrm{~nm}$ and a high-pass WG 280 filter from Schott. Therefore, Mie scattering is spectrally removed and only fluorescence between 280 and $420 \mathrm{~nm}$ is collected, that is, the whole fluorescence of kerosene (i.e., fluorescence from mono- and di-aromatics). The second camera uses a custom-made bandpass filter in the range 260-420 nm and a WG 305 filter from Schott. This allows one to spectrally remove Mie scattering and to collect fluorescence from di-aromatics only (i. e., between 305 and $420 \mathrm{~nm}$ ). Each camera is interfaced to a personal computer used to control the camera and to record images. 


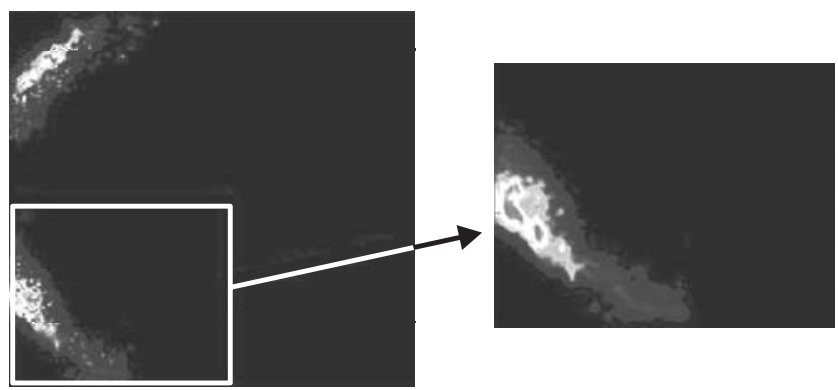

(a)

$(b)$

Figure 4 Fluorescence intensity emitted by kerosene vapor and droplets in the combustor $(a)$; example of the removal of droplet fluorescence intensity $(b), 480 \mathrm{~K}$ and $0.45 \mathrm{MPa}$ (pilot only). (Refer color plate, p. XV.)

Figure $4 a$ presents a typical instantaneous raw image of kerosene fluorescence after illumination of the flow in the combustor by the laser sheet from top to bottom. The red dots, representing large intensities, correspond to droplets, while fuel vapor is displayed with a false colorscale. The gain of both ICCD cameras is adjusted to keep the energy recorded by the array detector proportional to the fluorescence signal issued from the liquid and gas phases, which prevents the ICCD cameras from local saturation and blooming induced by the liquid kerosene fluorescence. For each flow condition, 200 single-shot images are acquired with each ICCD camera and the maps of mean fluorescence (either from kerosene or $\mathrm{OH}$ radical) presented in this paper result from the average over these 200 single-shots.

Raw fluorescence images are corrected for background luminosity, nonuniformities in the collection optics, and inhomogeneity in the laser sheet profile. An average background image is acquired with the laser sheet "on" in hot air. Subtraction of this image from the fluorescence image accounts for laser scattering and other background luminosity. An average background image is also acquired with the laser sheet "off" and the flame "on" in order to remove chemiluminescence emission from the flame. Finally, with the present experiments, it is necessary to add an extra routine which takes the presence of kerosene droplets in the flow into account. Due to the density difference between the liquid and vapor phases of kerosene, fluorescence signals are significantly larger for the liquid phase. As a result, there is a strong intensity gradient between a droplet and its surrounding vapor. The present authors take advantage of this feature to identify the location of droplets and to eliminate the fluorescence signal from the liquid phase which is initially set to zero. The fluorescence signal at the droplet location is then interpolated over the droplet area using the value of fluorescence intensity from kerosene vapor at the first pixel around the droplet 
both in the radial and axial directions. Example of this processing is shown in Fig. $4 b$.

\section{RESULTS}

This section presents simultaneous PLIF measurements of kerosene and OH radical at the outlet of the multipoint injector for different operating conditions. Both axial and radial measurements have been performed. However, only axial results are presented here due to space limitations.

In the first part, spatial correlation between kerosene and $\mathrm{OH}$ fluorescence is discussed.

The second part of the section presents the influence of combustion parameters (temperature, pressure, and fuel split between the pilot and the main injectors) on kerosene and $\mathrm{OH}$ spatial distributions.

\subsection{Correlation Between $\mathrm{OH}$ and Kerosene Fluorescence}

For axial measurements, the laser sheet propagates from the top to the bottom of the combustor and it is located on its vertical axis. For radial measurements, the laser sheet propagates from right to left on the images across the combustor, at different distances downstream from the injector. The focal plane of the images is located on the combustor axis. The physical dimension of the fluorescence images (OH or kerosene) in Figs. 5 to 8 is the same. However, it cannot be given in this paper for confidentiality reasons: the industrial partner does not want to unveil information to potential competitors. The aspect ratio (width/height) of each fluorescence image is 0.53 .

Figure 5 shows a comparison between axial single-shot fluorescence images of $\mathrm{OH}$ radical and kerosene for two conditions in terms of temperature and pressure. The red contour is used to define the spatial contours of kerosene vapor at the outlet of the injector. The pilot injector is located a few millimetres upstream from the main injector and, therefore, the pilot flame in Fig. $5 a$ burns upstream from the region visualized by the ICCD cameras. Although information is missing in that region, it is believed that kerosene radially spreads close to the swirler walls immediately after the outlet of the pilot injector. In Fig. $5 b$, the main injector has a wide angle and kerosene vapor is mainly located at the edge of the bowl due to swirling effects.

As can be seen, for all the conditions investigated, a good spatial correlation is obtained between the distribution of kerosene vapor and the location of $\mathrm{OH}$ radical, and the respective images can be compared in detail. As a matter of fact, for a given condition, small scale structures due to local high levels of turbulence can be observed at the same position at both images. In particular, it 


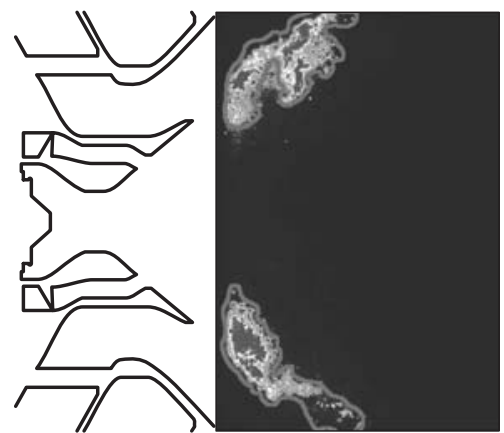

(a)

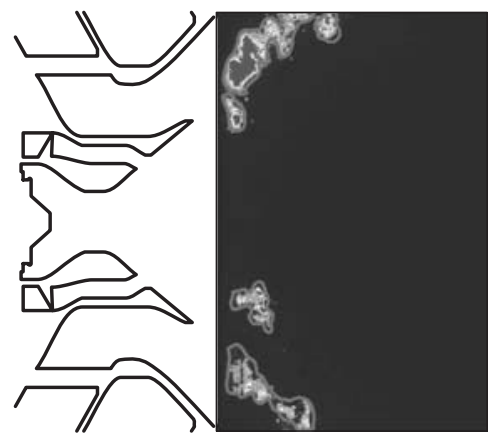

(c)

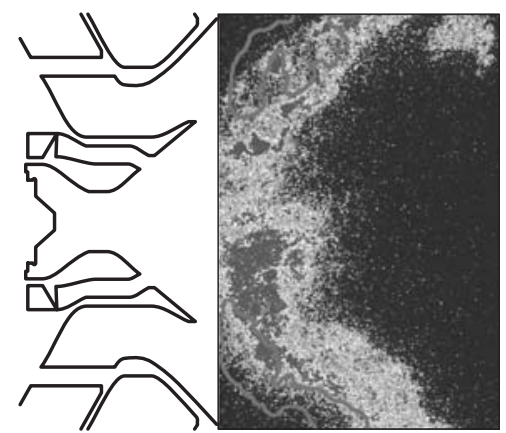

(b)

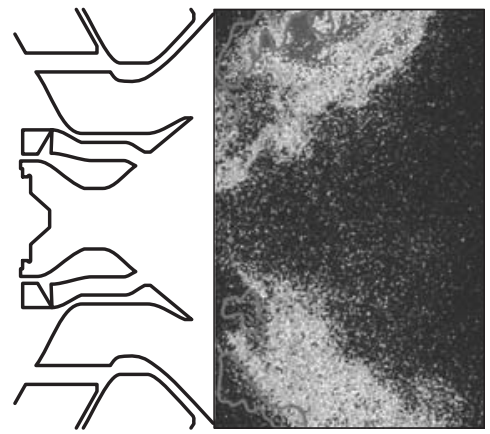

(d)

Figure 5 Axial instantaneous images of kerosene (left column) and $\mathrm{OH}$ radical (right column) fluorescence for different operating conditions: $(a)$ and $(b) 480 \mathrm{~K}$ and $0.45 \mathrm{MPa}$ (pilot only); and $(c)$ and $(d) 590 \mathrm{~K}$ and $0.95 \mathrm{MPa}\left(\Phi_{\text {pilot }} / \Phi_{\text {main }}=1\right)$. (Refer color plate, p. XV.)

is remarkable that kerosene fuel is present at larger distance than $\mathrm{OH}$ radical, which suggests that combustion occurs on the inner side of the cone delimitating kerosene. Although $\mathrm{OH}$ radical is present both in the flame front and in the region of hot gases, the combined analysis of the simultaneous fluorescence images of kerosene and $\mathrm{OH}$ radical allows determining the position of the flame front. Indeed, it is noticed that the flame front appears at the location where kerosene vapor vanishes, and no "dark zone" is visible. This confirms that, unlike surrogate fuels such as acetone, that pyrolyse at significant distance upstream from the flame front, aromatics are consumed within the flame front and their signal remains detectable at temperatures higher than $1000 \mathrm{~K}$. Therefore, in the following, the term "flame front" will refer to the outer edge of the region where $\mathrm{OH}$ radical is present. 


\subsection{Influence of Combustion Parameters}

Figure 6 shows axial single-shot images of $\mathrm{OH}$ radical fluorescence for various conditions in terms of temperature, pressure, and fuel split between the pilot and the main injectors. As can be seen, the flame front is highly stretched by turbulence and wrinkled structures are clearly identified. In Fig. 5a, only the pilot injector is used and, therefore, the flame front is located close to the injector axis, and exhibits a cone-like shape. By contrast, pilot and main injectors are operated with the same equivalence ratio in Fig. $5 b$ and a double flame structure is noticeable at the image. There are indeed two flame fronts: the one close to the axis comes from the pilot injector, whereas the peripheral flame front can be attributed to the main injector. In Fig. $6 c$, kerosene fuel is mainly injected through the main injector and, therefore, the flame front is located at the outer part of the injector.

Figures 7 and 8 show the mean images obtained after averaging over 200 single laser-shots for the same operating conditions as in Fig. 6. These images are corrected for laser absorption across the combustor using the classical BeerLambert's law, assuming that the flame shape and the spatial distribution of kerosene fuel are axisymmetric. This assumption is confirmed by radial measurements (not shown here). Each mean image is normalized by its maximum value and it is displayed on a black-to-red colorscale, where black color corresponds to a zero species concentration and red color indicates the maximum concentration.

As can be seen in Fig. 7, when temperature and pressure increase, the flame tends to slightly move away from the injector. Note that in Figs. $7 a$ and $7 b$, the

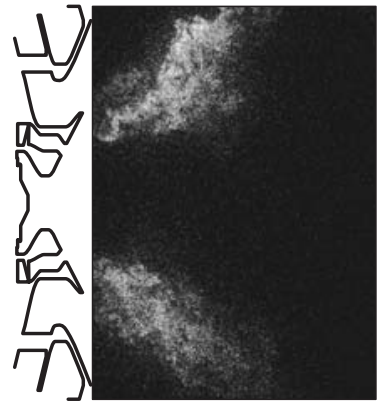

(a)

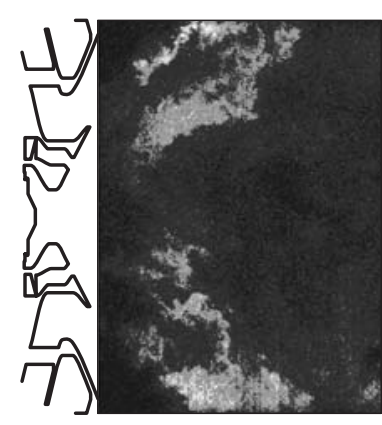

(b)

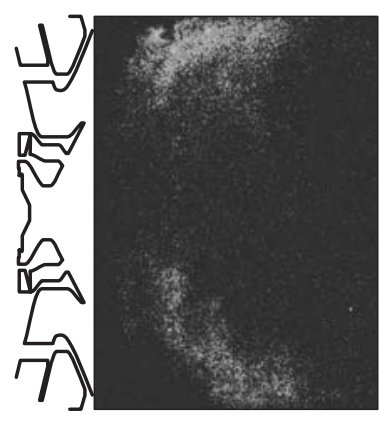

(c)

Figure 6 Axial instantaneous images of $\mathrm{OH}$ radical fluorescence for various operating conditions: (a) $480 \mathrm{~K}$ and $0.45 \mathrm{MPa}$ (pilot only); (b) $590 \mathrm{~K}$ and $0.95 \mathrm{MPa}$ $\left(\Phi_{\text {pilot }} / \Phi_{\text {main }}=1\right)$; and $(c) 730 \mathrm{~K}$ and $2.2 \mathrm{MPa}\left(\Phi_{\text {pilot }} / \Phi_{\text {main }}=0.1\right)$. (Refer color plate, p. XVI.) 


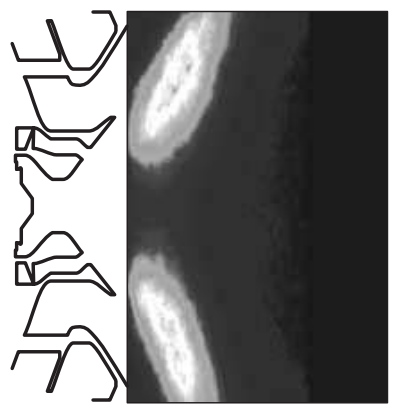

(a)

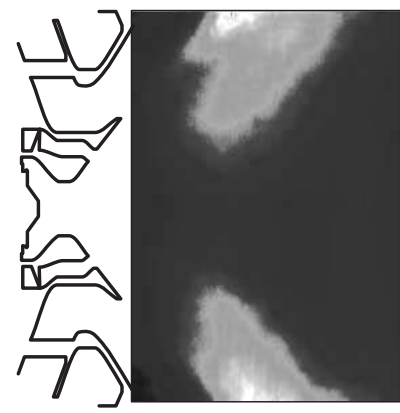

(b)

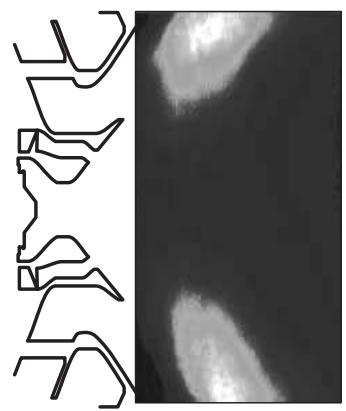

(c)

Figure 7 Axial mean images of $\mathrm{OH}$ concentration for various operating conditions: (a) $480 \mathrm{~K}$ and $0.45 \mathrm{MPa}$ (pilot only); (b) $590 \mathrm{~K}$ and $0.95 \mathrm{MPa}\left(\Phi_{\text {pilot }} / \Phi_{\text {main }}=1\right.$ ); and $(c) 730 \mathrm{~K}$ and $2.2 \mathrm{MPa}\left(\Phi_{\text {pilot }} / \Phi_{\text {main }}=0.1\right)$. Averaging is performed over 200 instantaneous images. (Refer color plate, p. XVI.)

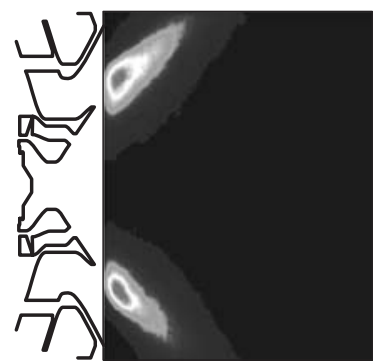

(a)

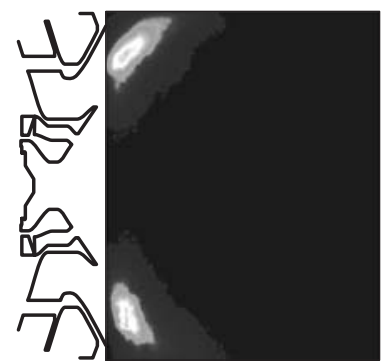

(b)

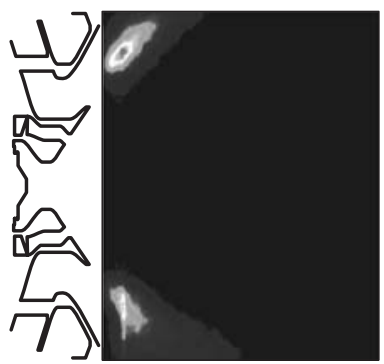

(c)

Figure 8 Axial mean images of equivalence ratio for various operating conditions: (a) $480 \mathrm{~K}$ and $0.45 \mathrm{MPa}$ (pilot only); (b) $590 \mathrm{~K}$ and $0.95 \mathrm{MPa}\left(\Phi_{\text {pilot }} / \Phi_{\text {main }}=1\right.$ ); and $(c) 730 \mathrm{~K}$ and $2.2 \mathrm{MPa}\left(\Phi_{\text {pilot }} / \Phi_{\text {main }}=0.1\right)$. Averaging is performed over 200 instantaneous images. (Refer color plate, p. XVI.)

pilot injector is operated, and this injector has a recess of several millimetres compared to the main injector. Therefore, the flame front due to the pilot injector is located closer along the axis than the flame front coming from the main injector. Nonetheless, in Fig. $7 c$, the flame front appears at a larger axial distance from the injector (a few millimeters) as temperature and pressure increase. Not surprisingly, as the fuel split between the pilot and the main injectors switches from $100 \%$ pilot to $\sim 100 \%$ main, the flame front gradually moves to a larger radial distance and changes from a cone-like to a bowl-like shape. It is remarkable that the double flame structure remains visible at the average image in Fig. $7 b$, 
which indicates that it is fairly repeatable from one image to the other. In addition, it is noticed that the flame exhibits a slight asymmetry between the upper and the lower parts of the combustor, which comes from unbalanced airflow through the injector due to the geometry of the kerosene injection strut.

Figure 7 also allows determining the flame angle and flame length for different operating conditions. It is noticed that the flame opens up as pressure and temperature increase and flame angle increases from $\sim 95^{\circ}$ to $\sim 135^{\circ}$. This evolution can be partly attributed to the gradual switch of the repartition of fuel loading between the pilot and the main injectors from $100 \%$ pilot to $\sim 100 \%$ main. In addition, flame length also tends to increase from Fig. $7 a$ to Fig. $7 c$. Nonetheless, fuel split, temperature, and air flowrates are different between all these conditions, and it is difficult to determine which parameter most influences the flame length.

Finally, very little fluorescence from $\mathrm{OH}$ radical is detected at the axis of the combustor, which suggests that $\mathrm{OH}$ concentration is very low at that position. Indeed, the recirculation zone located at the outlet of the injector entrains burnt gases and dilution air close to the injector and helps stabilizing the flame. Dilution air quenches chemical reactions in the burnt gases leading to the reduction of $\mathrm{OH}$ concentration in the gas mixture recirculating close to the injector.

Similar to the observations with $\mathrm{OH}$ radical, Fig. 8 shows that when fuel injection gradually switches from $100 \%$ pilot to $\sim 100 \%$ main, kerosene vapor gradually moves to larger radial distances. In addition, as temperature and pressure increase, the spatial extent of kerosene vapor reduces. Although values of local equivalence ratio are representative of droplet evaporation and mixing efficiency between fuel vapor and air, Figs. $8 a$ to $8 c$ cannot be compared straightforward. Indeed, the operating conditions given in Table 1 have different overall equivalence ratio. Nonetheless, air inlet temperature is higher at $2.2 \mathrm{MPa}$ and this enhances fuel evaporation, which leads to a larger local equivalence ratio.

\section{CONCLUDING REMARKS}

Simultaneous PLIF measurements applied to $\mathrm{OH}$ radical and kerosene were successfully performed at the outlet of a multipoint injector, for various operating conditions (temperature up to $730 \mathrm{~K}$ and pressure up to $2.2 \mathrm{MPa}$ ). Experiments demonstrate the potential of PLIF technique to visualize simultaneously the flame structure and the spatial distribution of kerosene vapor concentration in a real aeronautical injection system operating at flight conditions. Results can be summarised as follows:

- application of OH-PLIF and kerosene-PLIF to a real aircraft injection system is demonstrated at pressure up to $2.2 \mathrm{MPa}$. Discrimination of fluorescence of monoaromatics and di-aromatics is also demonstrated exper- 
imentally, which makes possible the quantitative analysis of the present results;

- when both the pilot and main injectors are operated with a similar equivalence ratio, the flame exhibits a dual structure and two separate flame fronts coming from the pilot and the main injectors are clearly visible. By contrast, when either the pilot or the main injector is operated, the flame front displays a single structure;

- as pressure and temperature increase, the flame front changes from a conelike to a bowl-like shape;

- results show good spatial correlation between the repartition of the kerosene vapor and the position of the flame front. The spatial removal of aromatics correlates with the production of $\mathrm{OH}$ radicals, which means that aromatics naturally present in kerosene (multicomponent fuel) matches the behavior of the parent fuel. No pyrolysis effect is observed; and

- future work will concern the extension of the PLIF-OH and PLIF-kerosene techniques to higher temperature $(900 \mathrm{~K})$ and pressure $(3.0 \mathrm{MPa})$.

\section{ACKNOWLEDGMENTS}

This work was performed within the "Towards Lean Combustion" program sponsored by the European Union under grant No. FP6-2003-Aero-1 with D. Chiron as program monitor and Snecma Moteurs as coordinator.

\section{REFERENCES}

1. Pilch, M., and C. A. Erdman. 1987. Use of breakup time data and velocity history data to predict the maximum size of stable fragments for acceleration-induced breakup of a liquid drop. Int. J. Multiphase Flow 13:741-57.

2. Lefebvre, A. H. 1989. Atomization and sprays. 1st ed. Hemisphere Publishing.

3. Lefebvre, A.H. 1995. The role of fuel preparation in low emission combustion. J. Eng. Gas Turb. Power 117:617-54.

4. Lefebvre, A. H. 1999. Gas turbines combustion. 2nd ed. Taylor \& Francis.

5. Correa, S. M. 1992. A review of NOx formation under gas-turbine combustion conditions. Combust. Sci. Technol. 87:329-62.

6. Löfström, C., J. Engström, M. Richter, C. F. Kaminski, P. Johansson, K. Nyholm, J. Hult, J. Nygren, and M. Aldén. 2000. Feasibility studies and application of laser/optical diagnostics for characterisation of a practical low-emission gas turbine combustor. ASME Paper No. 2000-GT-0124. 
7. Greenhalgh, D. A. 2000. Laser imaging of fuel injection systems and combustors. Proceedings of the Institution of Mechanical Engineers. Part A. J. Power Energy 214:367-76.

8. Michou, Y., I.S. Carvahlo, C. Chauveau, and I. Gökalp. 1999. Experimental study of lean premixed and prevaporised turbulent spray combustion. AIAA Paper No. 1999-332.

9. Becker, J., and C. Hassa. 2003. Liquid fuel placement and mixing of generic aeroengine premix module at different operating conditions. J. Eng. Gas Turb. Power 125:901-08.

10. Krämer, H., F. Dinkelacker, and A. Leipertz. 1999. Optimization of the mixing quality of real size gas turbine burner with instantaneous planer laser-induced fluorescence imaging. ASME Paper No. 99-GT-135.

11. Stufflebeam, J.H., D. W. Kendrick, W. A. Sowa, and T.S. Snyder. 2002. Quantifying fuel/air unmixedness in premixing nozzles using an acetone fluorescence technique. J. Eng. Gas Turb. Power 124:39-45.

12. Hicks, Y.R., R. J. Locke, R. C. Anderson, M. Zaller, and H. J. Schock. 1997. Imaging fluorescent combustion species in gas turbine flame tubes: On complexities in real systems. AIAA Paper No.97-2837.

13. Hicks, Y.R., R. J. Locke, and R.C. Anderson. 2000. Optical measurement and visualization in high-pressure, high-temperature, aviation gas turbine combustors. NASA/TM-2000-210377.

14. Löfström, C., H. Kaaling, and M. Aldén. 1996. Visualization of fuel distributions in premixed ducts in a low-emission gas turbine combustor using laser techniques. 26th Symposium (International) on Combustion Proceedings. 2787-93.

15. Arnold, A., R. Bombach, W. Hubschmid, A. Inauen, and B. Käppeli. 2000. Fueloil concentration in a gas turbine burner measured with laser-induced fluorescence. Exp. Fluids 29:468-77.

16. Baranger, P., M. Orain, and F. Grisch. 2005. Fluorescence spectroscopy of kerosene vapour: Application to gas turbines. AIAA Paper No. 2005-828.

17. Orain, M., H. Verdier, and F. Grisch. 2006. Equivalence ratio measurements in kerosene-fuelled LPP injectors using planar laser induced fluorescence. 13th Symposium (International) on Application of Laser Techniques to Fluid Mechanics. Lisbon (Portugal). Paper 1220.

18. Hanson, R. K. 1986. Combustion diagnostics: Planar imaging techniques. 21st Symposium (International) on Combustion Proceedings. 1677-91.

19. Atakan,B., J. Heinze, and U.E. Meier. 1997. OH laser-induced fluorescence at high pressures: Spectroscopic and two-dimensional measurements using the $A-X(1,0)$ transition. J. Appl. Phys. 64:585-91.

20. Frank, J. H., M. F. Miller, and M. G. Allen. 1999. Imaging of laser-induced fluorescence in a high-pressure combustor. AIAA Paper No. 99-0773.

21. Birks, J. B. 1970. Photophysics of aromatic molecules. London: Wiley-Interscience.

22. Koban, W., J. D. Koch, R. K. Hanson, and C. Schulz. 2005. Oxygen quenching of toluene fluorescence at elevated temperatures. J. Appl. Phys. 80:777-84. 